\title{
O avô e a avó na visão dos netos
}

The grandfather and grandmother as seen by

their grandchildren

El abuelo y la abuela en la visión de los nietos

Rosa Maria da Motta Azambuja

Elaine Pedreira Rabinovich

RESUMO: Este artigo objetivou descrever a visão dos netos de suas relações com seu avô e sua avó, com base na dimensão pessoa da teoria bio-ecológica, de Bronfenbrenner. O estudo, de abordagem qualitativa, contou com a participação de seis avós e seus netos em idade escolar. Para a coleta de dados, foram utilizados instrumentos da perspectiva educacional (roda de conversa e álbum de imagens). Os principais resultados apontam que há diferença nas relações intergeracionais em função de gênero.

Palavras-chave: Avô e avó; Netos; Teoria Bio-ecológica.

ABSTRACT: This article aims to describe the vision of the grandchildren of his relations with their grandfather and grandmother based on the dimension of the person bio-ecological theory of Bronfenbrenner. This qualitative study included the participation of six grandparents and grandchildren of school age. For data collection, instruments of educational perspective were used (conversation wheel and picture album). The main results show that there are differences in intergenerational relationships by gender

Keywords: Grandmother and Grandfather; Grandchildren; Bioecological theory. 
RESUMEN: Este artículo objetivó describir la visión de los nietos de sus relaciones con su abuelo y su abuela, con base en la dimensión persona de la teoría bioecológica, de Bronfenbrenner. El estudio, de abordaje cualitativo, contó con la participación de seis abuelos y sus nietos en edad escolar. Para la recolección de datos, se utilizaron instrumentos de la perspectiva educativa (rueda de conversación y álbum de imágenes). Los principales resultados apuntan que hay diferencia en las relaciones intergeneracionales en función de género.

Palabras-chave: Abuelo y abuela; Netos; Teoría bioecológica.

\section{Introdução}

Nas relações entre avós e netos, o gênero aparece como uma dimensão da pessoa, fornecendo compreensão ao convívio intergeracional. Manifesta-se nas diferenças e semelhanças entre avós e avôs; no modo de contato das linhagens maternas e paternas; na preferência dos gêneros na percepção dos netos. Os relatos das crianças são testemunhos de suas próprias escolhas, sendo que as falas das crianças, suas brincadeiras, desenhos, e muitas vezes até mesmo seu silêncio, revelam suas percepções em relação ao mundo que as cerca (Sherer, 2009, p. 7).

Buscando responder a estas questões, pesquisas voltadas aos relatos de netos crianças visaram a compreender a distinção das atividades realizadas pelos avós de gêneros masculino e feminino. Assim, Ramos (2012) entrevistou 36 meninos e meninas, na faixa etária entre oito e dez anos, oriundos de família nucleares, monoparentais, reconstituídas e conviventes e pertencentes à classe média da cidade de Porto Alegre, RS, Brasil, cujo objetivo buscou compreender como as relações de gênero operam nas relações entre as gerações a partir da perspectiva dos netos crianças. Os resultados mostraram um forte entrelaçamento entre as relações de gênero e as relações intergeracionais. De um lado, as relações entre avós e netos são influenciadas pelas afinidades e pelos estilos de avosidade desempenhados pelos avôs e pelas avós; de outro, esta relação é perpassada pelas relações familiares e pela própria linhagem na qual os avós se encontram. 
Os avôs são menos envolvidos no cuidado intergeracional, mas foi possível observar um movimento dos homens neste sentido, que, normalmente, se direciona para atividades fora do ambiente doméstico - como buscar ou levar o neto à escola - e a brincadeiras mais dinâmicas e perigosas. Estes são aspectos relevantes tanto para os meninos quanto para as meninas, não havendo grandes diferenças de gênero quanto às expectativas e experiências intergeracionais das crianças entrevistadas.

Moreira, Rabinovich, \& Silva (2009) em estudo que envolveu a participação de 60 crianças, com idade variando entre 6 e 10 anos, sendo 24 do sexo masculino e 36 do feminino, cujos pais tinham nível sócio-educacional entre baixo e médio, residentes no Estado da Bahia, Região Nordeste, a metade morava na capital e a outra metade em cidades do interior. O objetivo do estudo foi investigar a concepção das crianças sobre sua definição dos membros da família, inclusive de avós. Os dados evidenciaram que, segundo os netos, o avô seria mais lúdico e a avó, mais afetiva e cuidadora.

Em estudos internacionais, Smorti, Tschiesner, \& Farneti (2012) entrevistaram 373 avós italianos (153 do sexo masculino; 220 do sexo feminino) com idade entre 53 e 88 anos, sendo 205 maternos, e 168 paternos, em centros de convivência para idosos em Bressanone, Itália, cujo objetivo foi investigar os sentimentos e atividades realizadas pelos avós do lado materno e paterno. Os resultados mostraram que os avós apresentam sentimentos positivos em relação aos netos, e atribuem uma grande importância a seu papel de educador e auxiliar. Quanto às atividades, a linhagem paterna realiza mais atividades compartilhadas do que a materna. Em relação ao tipo de atividades, as mulheres realizam atividades linguísticas, como contar histórias de fábulas ou sobre sua própria família, enquanto que os homens se dedicam às atividades ao ar livre e à prática esportiva.

Em Portugal, Rodrigues (2008) entrevistou 17 avós e 17 mães, todas pertencentes ao mesmo núcleo familiar. As avós, tanto maternas como paternas, deveriam estar presentes nos cuidados aos seus netos. $\mathrm{O}$ estudo teve como objetivo compreender qual a importância das avós no contexto familiar, e a sua importância no cuidar das crianças num contexto rural, tendo sido escolhida a localidade de Foros de Salvaterra, no concelho de Salvaterra de Magos. Os resultados apontaram que as avós continuam sendo muito importantes na transmissão de saberes culturais, apoio financeiro, e cuidados infantis. 
Há um maior envolvimento dos homens nas tarefas domésticas e nos cuidados infantis, como banho, o adormecimento, o vestir, a alimentação e mesmo atividades lúdicas. A avó que mais ajuda é aquela que está mais presente, independentemente de ser a avó materna ou paterna.

No entanto, pode-se dizer que os estudos envolvendo avós e netos e gênero são ainda incipientes. Nota-se que, no Brasil, há uma tendência de os homens se envolverem em atividades lúdicas com os netos mais do que propriamente no cuidado doméstico (Pedrosa, 2006; Moreira, Rabinovich, \& Silva, 2009; Ramos, 2011). Contudo, em nível internacional, além de se constatar a tendência lúdica dos avôs e a transmissão de saberes pelas avós, é possível perceber a participação dos avôs em atividades ao ar livre e a prática esportiva (Rodrigues, 2008; Smorti, Tschiesner, \& Farneti, 2012). Nesta direção, o presente estudo pretende responder à questão, contemplando o seu objetivo: como se dão as relações com o avô e com a avó do ponto de vista dos netos? Em que se assemelham e em que diferem?

Bronfenbrenner compreende a ecologia do desenvolvimento humano como uma "mudança duradoura na maneira pela qual uma pessoa percebe e lida com o seu ambiente" (1996, p. 5). Consiste em um processo de progressiva e mútua acomodação entre o ser humano ativo, em crescimento, e as propriedades mutantes dos ambientes imediatos. Esta interação entre a pessoa e o meio ambiente se caracteriza pela reciprocidade, sendo, portanto, bidirecional.

Os níveis estruturais do mapa ecológico são: o microssistema, o mesossistema, o exossistema e o macrossistema, sendo que será dada ênfase na análise dos elementos do microssistema. O microssistema "é um padrão de atividades, papéis e relações interpessoais experienciados pela pessoa em desenvolvimento num dado ambiente com características físicas e materiais específicos" (Bronfenbrenner, 1996, p. 18). Trata-se, portanto, de um ambiente ou local em que o indivíduo pode estabelecer interações face a face; neste estudo, a relação entre avós e netos.

Em ecologia humana, a díade é considerada uma unidade básica de análise. $\mathrm{O}$ referido autor considera-a como a estrutura interpessoal mais simples e, consequentemente, como o contexto mais imediato do desenvolvimento humano. Uma das mais expressivas contribuições da abordagem ecológica refere-se às propriedades atribuídas à díade. 
Segundo Bronfenbrenner (1996), três características são essenciais para o desenvolvimento de atividade conjunta: reciprocidade, equilíbrio de poder e relação afetiva.

A reciprocidade está relacionada à maneira como os participantes interagem entre si, como um influencia o desenvolvimento do outro, pois, quando um membro de uma díade sofre um processo de desenvolvimento, o outro também o sofrerá.

Numa relação diádica, um membro pode ser mais influente que o outro, embora a ideia de reciprocidade sugira igualdade de poder. O ideal é que essa maior influência seja alternada entre os participantes da díade, havendo, então, um equilíbrio de poder. Estudos mostram que os netos recebem ajuda nos deveres da escola, auxiliam os avós na prestação de serviços como tirar os pratos, enxugar os pratos, guardar os brinquedos no lugar certo. Enquanto, no momento dos jogos, são os netos que exercem maior influência sobre a situação, passando a dominar a situação (Contrin, 2006; Ramos, 2011).

Bronfenbrenner enfatiza que a participação em uma interação diádica oferece a oportunidade para aprender a lidar com a relação de poder, além de desenvolver capacidade para o exercício de controle sobre uma dada situação. No caso dos netos, estes podem receber, por exemplo, conselhos dos avós. "Na medida em que ocorrem interações desenvolvem-se sentimentos diferenciados e duráveis entre seus membros" (1996, p. 47). Nessa medida, pode-se pressupor que, dessas trocas lúdicas, uma relação de trocas de longo prazo possa estar sendo estabelecida.

Para o referido autor, relações afetivas positivas e genuínas evoluem para um tipo de relação denominada díade primária, que é o tipo mais duradouro de interação. As díades primárias existem para os participantes, mesmo que eles não estejam fisicamente juntos. Essa convivência, sob a ótica proposta, pode ser vista como relações microssistêmicas, envolvendo contatos de proximidade (com interações face a face) entre avós e netos, estabelecidos no cotidiano e em seu ambiente imediato, como também em mesossistemas, em função da interação existente em outros contextos, como a moradia dos avós e locais onde circulam.

É importante mencionar que as mesmas propriedades que definem um mesossistema protetor ao desenvolvimento humano - formas de ligação, comunicação e disponibilidade de conhecimento - acontecem em outras atividades realizadas conjuntamente, ampliando o referencial de experiência dos netos. 
Segundo a teoria bio-ecológica, essas comunicações inter-ambientais podem ocorrer de forma unilateral ou bilateral, dependendo das características e condições dos ambientes em que os comunicantes se encontram.

Portanto, as concepções fundamentais do modelo ecológico de Bronfenbrenner pressupõem que, além destes indivíduos e seus ambientes estarem em mútua e recíproca interação através dos processos proximais, é preciso atentar para a importância do aprendizado do que ele chama de "experiência humana" (1996, p. 43), essencial para o desenvolvimento individual e coletivo, com vistas ao aprendizado da convivência, das práticas de cuidados de si, de outrem e dos ambientes, com prioridade para a solidariedade.

Nesses termos, pode-se afirmar que os avós que cuidam das crianças funcionam efetivamente como contextos de desenvolvimento humano, na medida em que contemplam um complexo de atividades, papéis e relações que caracteriza o ambiente ecológico (Bronfenbrenner, 1996).

De forma concisa, duas condições ambientais e sociais são importantes para o desenvolvimento do ser humano:

1) cuidador - além da rotina, que necessita ser controlada, a criança necessita de alguém que realize atividades em conjunto;

2) papel de desempenho dos avós - tem sido bastante destacado pela literatura. A peculiaridade desses membros familiares está relacionada à maior experiência que possuem quanto à criação de outras pessoas e por subsidiarem apoio emocional e instrumental ao grupo, dado o seu conhecimento acerca da situação de cuidado.

Em resumo, de todos os ambientes que ajudam a construir o humano, a família provê as condições desenvolvimentais mais importantes: o amor e o cuidado que a criança necessita para fazer florescer o seu potencial (Bronfenbrenner, 2004).

Já nas décadas posteriores, durante as quais o referido autor ampliou a sua abordagem, as novas reformulações do modelo ecológico de desenvolvimento humano, realizadas por Bronfenbrenner e Morris (1998), incluem uma nova forma de olhar as propriedades da pessoa em desenvolvimento.

Nesta teoria, o uso do termo do desenvolvimento humano é revisto e complementado: "desenvolvimento refere-se à estabilidade e mudança nas características biopsicológicas dos seres humanos durante o ciclo de suas vidas e através das gerações" (Bronfenbrenner, 1995, p. 995). 
Segundo o autor, o processo se estende no curso da vida, através de gerações sucessivas, e do tempo histórico, tanto no passado como no futuro (Bronfenbrenner, 2004).

Outro aspecto proposto no novo modelo é o construto teórico "processos proximais", entendido como "formas particulares de interação entre organismo e ambiente, que operam ao longo do tempo e compreendem os primeiros mecanismos que produzem o desenvolvimento humano" (Bronfenbrenner, \& Morris, p. 994). No modelo bio-ecológico, são reapresentados quatro aspectos multidirecionais inter-relacionados, o que é designado como modelo PPCT: "pessoa, processo, contexto e tempo".

A dimensão pessoa ressalta as características da pessoa em dado momento de sua vida, sendo uma função conjunta das características individuais e do ambiente ao longo do curso de sua vida naquele dado momento (Bronfenbrenner, 1996, p. 90). Há três núcleos básicos: demanda, recursos e força.

No núcleo demanda, apresentamos as diferenças e semelhanças de gênero. No núcleo recursos, destacamos os modos de contato nas linhagens. E, por fim, no núcleo força evidenciamos as preferências dos gêneros na escolha das crianças.

\section{O estudo}

Este trabalho consistiu de um estudo de abordagem qualitativa. O estudo foi realizado com alunos de uma escola privada do Ensino Fundamental na cidade do Salvador, Bahia. A instituição se localiza em um bairro nobre da cidade, atende a um público de classe média alta, e oferece sistema de bolsa para alunos filhos dos funcionários de baixa renda. A coleta de dados foi feita nas dependências da instituição. Para a localização das famílias, a indicação deu-se pela coordenadora. Foram participantes do estudo seis crianças, três estudantes do sexo feminino e três do sexo masculino, na faixa etária de 6 a 9 anos de idade, de classe média e baixa, juntamente com suas avós, em uma escola particular de classe média na cidade do Salvador, Bahia. Adotou-se como critério de inclusão dos participantes os netos conviverem com os avós na mesma cidade.

Como modo de acesso aos participantes, foram realizados dois procedimentos: roda de conversa e álbum de imagens da perspectiva educacional. 
Roda de conversa - Para ouvir as crianças em grupo sobre suas próprias experiências e legitimar suas narrativas de convivência com os avós como fonte de pesquisa, realizamos a Roda de Conversa. Nesse contexto, o diálogo é um momento singular de partilha, uma vez que pressupõe um exercício de escuta e fala. As colocações de cada participante são construídas a partir da interação com o outro, sejam para complementar, discordar, ou mesmo para concordar com a fala imediatamente anterior. Questionou-se sobre "Como é a convivências com os avós?" e "O que vocês fazem juntos?”

Álbum de Imagens - Para suscitar narrativas individuais, foi apresentado individualmente a cada criança um álbum de imagens, contendo gravuras, para seleção de imagens que representariam os tipos de atividades que fazem juntos com avós. Através da apresentação de vinte gravuras, pretendeu-se levar a criança a se projetar nos personagens para a percepção da relação entre avós e netos. O instrumento consiste na escolha da gravura com o qual a criança mais se identifica.

A pesquisa foi submetida e aprovada pelo Comitê de Ética em Pesquisa com Seres Humanos da Universidade Católica de Salvador (UCSAL), sob o CAAE n. ${ }^{\circ}$ 35769214.3.0000.5628. Em seguida, tanto as mães, avós e crianças participantes assinaram o Termo de Consentimento e Assentimento Livre e Esclarecido.

A fim de dar início à coleta de dados, cada membro da família teve a oportunidade de responder à sua entrevista individualmente, no primeiro dia. Ficaram agendados com a coordenadora escolar o dia e horário para o encontro com as crianças. Vale ressaltar que a participação ocorreu somente com a presença feminina das avós, sendo que o convite era para o avô e avó. A duração das entrevistas com as avós foi de 20 a 45 minutos, e com as crianças, de 60 minutos.

Seis avós eram do sexo feminino, sendo quatro da linhagem materna, uma paterna e uma sócio-afetiva; a média das idades era 64,5 anos; quanto à situação conjugal, três eram casadas, duas viúvas e uma divorciada; quanto à escolaridade, duas possuíam ensino superior, três o ensino médio e uma, o ensino fundamental; em relação à profissão, três eram aposentadas, uma pensionista, uma autônoma e uma funcionária pública; já a classe social, três eram de classe socioeconômica média e três de classe socioeconômica baixa. 
Além disso, as duplas foram classificadas por: avós de tempo integral: cuidam integralmente de seus netos; avós: sistemáticas: cuidam dos netos em atividades realizadas sistematicamente, como levar à escola; avós esporádicas: convivem com netos quando solicitadas ou por desejo próprio (ver Quadro 1 e Quadro 2).

Quadro 1 - Perfil sociodemográfico das avós pesquisadas - Salvador, Bahia, 2015

\begin{tabular}{|c|c|c|c|c|c|c|c|}
\hline \multirow{2}{*}{$\begin{array}{l}\text { TIPO DE } \\
\text { CUIDADO }\end{array}$} & \multicolumn{7}{|c|}{ AVÓS } \\
\hline & Idade & Escolaridade & Profissão & $\begin{array}{l}\text { Situação } \\
\text { Conjugal }\end{array}$ & Moradia & Linhagem & $\begin{array}{c}\text { Classificação } \\
\text { Socioeconômica }\end{array}$ \\
\hline \multirow{2}{*}{ Integral } & 65 & Ensino Médio & $\begin{array}{l}\text { Professora } \\
\text { aposentada }\end{array}$ & Casada & Casa & Socioafetiva & B2 \\
\hline & 70 & $\begin{array}{c}\text { Ensino } \\
\text { Fundamental }\end{array}$ & Pensionista & Viúva & Casa & Materna & $\mathrm{C} 1$ \\
\hline \multirow{2}{*}{ Sistemática } & 63 & Ensino Superior & $\begin{array}{c}\text { Bancária } \\
\text { aposentada }\end{array}$ & Divorciada & Apto & Materna & B2 \\
\hline & 56 & Ensino Médio & Autônoma & Casada & Casa & Materna & $\mathrm{C} 1$ \\
\hline \multirow{2}{*}{ Esporádica } & 72 & Ensino Médio & $\begin{array}{l}\text { Servidora } \\
\text { pública } \\
\text { aposentada }\end{array}$ & Viúva & Apto4 & Paterna & B2 \\
\hline & 61 & Ensino Superior & $\begin{array}{l}\text { Assistente } \\
\text { Social }\end{array}$ & Casada & Apto & Materna & $\mathrm{C} 1$ \\
\hline
\end{tabular}

Nota: Classe B2: renda média familiar de R\$ 3.118; Classe C1: renda familiar de R\$ 1.861, segundo dados do Critério de Classificação Econômica Brasil (Associação Brasileira de Empresas de Pesquisa, 2014).

Fonte: Elaboração própria

Quadro 2 - Perfil sociodemográfico dos netos pesquisados - Salvador, Bahia, 2015

\begin{tabular}{|c|c|c|c|c|c|c|c|c|}
\hline $\begin{array}{l}\text { Tipo } \\
\text { Cuidado }\end{array}$ & Nome & Gênero & Idade & $\begin{array}{c}\text { Ano } \\
\text { escolar }\end{array}$ & $\begin{array}{l}\text { Corrêsiden } \\
\text { cia }\end{array}$ & $\begin{array}{l}\text { Contato avós } \\
\text { maternos }\end{array}$ & $\begin{array}{l}\text { Contato avós } \\
\text { paternos }\end{array}$ & $\begin{array}{c}\text { Classificação } \\
\text { Socioeconômica }\end{array}$ \\
\hline \multirow{2}{*}{ Integral } & I (1) & Feminino & 7 & $3^{\circ}$ & $\begin{array}{l}\text { Avós } \\
\text { adotivos }\end{array}$ & Nunca & Nunca & B2 \\
\hline & I (2) & Masculino & 9 & $5^{\circ}$ & $\begin{array}{l}\text { Avó e } \\
\text { mãe }\end{array}$ & Diariamente & Nunca & $\mathrm{C} 1$ \\
\hline \multirow{3}{*}{ Sistemático } & \multirow[t]{2}{*}{ S (1) } & \multirow[t]{2}{*}{ Masculino } & \multirow[t]{2}{*}{8} & \multirow[t]{2}{*}{$4^{\circ}$} & \multirow[t]{2}{*}{ Pais } & $\begin{array}{l}\text { Avó } \\
\text { Final de } \\
\text { semana }\end{array}$ & \multirow[t]{2}{*}{ Às vezes } & \multirow[t]{2}{*}{$\mathrm{B} 2$} \\
\hline & & & & & & $\begin{array}{l}\text { Avô } \\
\text { Às vezes }\end{array}$ & & \\
\hline & $S(2)$ & Feminino & 6 & $2^{\circ}$ & Pais & $\begin{array}{l}\text { Dias de } \\
\text { semana }\end{array}$ & Nunca & $\mathrm{C} 1$ \\
\hline \multirow{2}{*}{ Esporádica } & $\mathrm{E}(1)$ & Masculino & 6 & $2^{\circ}$ & Pais & Às vezes & Diariamente & B2 \\
\hline & $E(2)$ & Feminino & 9 & $5^{\circ}$ & Pais & Diariamente & Às vezes & $\mathrm{C} 1$ \\
\hline
\end{tabular}

Fonte: Elaboração própria 


\section{Análise}

A análise foi realizada por meio de derivações sucessivas, orientadas pela teoria bio-ecológica, partindo de dados concretos decorrentes dos dados obtidos por meio dos instrumentos utilizados, em uma direção cada vez mais abstrata, conforme poderá ser apreciado nos tópicos que se seguem: resultados (dados obtidos), discussão (integração destes dados com a teoria) e síntese (integração dentro da teoria).

\section{Núcleo Demanda - as diferenças e semelhanças entre avós-mulheres e avôs-homens}

\section{Avós-mulheres}

Para as crianças, as diferenças são dadas pela divisão do trabalho: "Avó faz comida e o avô me leva na escola" (neta integral); "Avó ensina o dever e o avô leva a passear" (neta sistemática); "Minha avó brinca comigo no computador e o meu avô joga totó no play" (neto esporádico).

As crianças observam que o espaço doméstico interno é muito mais domínio da avó; contudo, quando os avôs ficam em casa, a imagem que os netos têm é a de um homem que "fica sentado, só assistindo televisão" (neta integral). Para a neta sistemática, os homens "ficam em casa, lendo jornal, porque a mulher fica fazendo as tarefas de casa". A avó, esteja ela trabalhando fora de casa ou aposentada, continua bastante ativa no espaço doméstico, dando continuidade às tarefas que, muitas vezes, ela desempenhou ao longo de toda a sua história de esposa e de mãe. "Eu também vejo isso" - conta o neto esporádico - "porque o meu avô ajuda, ele faz as compras no mercado, enquanto a minha avó faz o almoço".

Segundo Saraceno e Naldini (2001), o casamento não dá origem apenas a uma vida a dois, mas, também, à divisão do trabalho, dos espaços, das competências, dos valores e dos destinos pessoais de homens e mulheres.

Ainda que alguns poucos avôs ajudem nas tarefas da casa, como o avô do neto esporádico, as horas destinadas ao trabalho doméstico diferem entre os sexos, o que é comprovado pelos dados do IBGE (2012): enquanto a média brasileira, em 2011, era de 39,2 horas, contra 43,4 dos homens, ela era de apenas 4,2 de diferença entre homens e mulheres. 
As mulheres sempre estiveram mais envolvidas com o cuidado da casa e dos filhos. Muitas dessas avós provavelmente foram socializadas em um sistema voltado à forte divisão de tarefas por gênero, como bem observa a neta integral: "A minha avó cuida bem mais do que o meu avô". As avós da linha materna têm geralmente maior envolvimento com os netos, embora importe a idade da avó, a sua saúde e a proximidade geográfica (Harper, 2006; Silva, 2010).

\section{Avôs-homens}

O lugar do avô se constitui a partir dos contextos socioculturais, como acontece na convivência, ainda que esta não seja uma constante no cotidiano. "Os seus relatos transmitem um patrimônio que se deixa para aquele que escuta: o neto. Numa relação na qual o passado tem valor, recobra significado no presente que se constrói" (Pedrosa, 2006, p. 42).

Atualmente, é fácil encontrar a convivência de até quatro gerações, concomitantemente. Nos países desenvolvidos e em vias de desenvolvimento, as configurações familiares mudaram radicalmente nas últimas décadas (Motta, 2004).

Dessa maneira, aumenta o número de avôs/avós e o número de anos que uma pessoa vai viver como avô/avó. É habitual, nos dias de hoje, compartilhar a vida adulta dos netos, criando novas modalidades vinculares de solidariedade mútua, nas quais, frequentemente, estes se transformam em seus cuidadores e/ou exercem uma função mediadora quando existem conflitos com a geração do meio (Goldfarb, \& Lopes, 2006).

Nas interações cotidianas, as crianças fazem muito menos referência aos seus avôs do que às suas avós, sendo possível constatar que os homens são menos envolvidos no cuidado intergeracional mencionado na fala dos netos, ainda que muitos tenham o compromisso de levá-los e buscá-los na escola: "O meu avô é quem me leva e me busca na escola" (neta integral). Contudo, costumam desempenhar tarefas mais auxiliares e paralelas, ajudando seus netos fora do espaço doméstico ou na fronteira entre o público e o privado. 
Contudo, quando estão dentro de casa costumam ser companheiros de TV e jogos, como declara a neta sistemática: "Assisto TV com meu avô e depois jogamos cartas"; "Quando a minha avó não tá para me ensinar o dever, peço ao meu avô" (neta integral). As diferenças de gênero no envolvimento com as crianças são facilmente percebidas por elas:

Neta integral (sobre os avós sócio-afetivos) - "Os meus avós são muito bons, mas tem uma diferença... eu vou explicar, quem cuida de mim é a minha avó e o meu avô fica na frente da TV, ela conversa mais comigo, se preocupa mais...".

Neta sistemática (sobre os avós maternos) -“O meu avô é diferente da minha avó, ele é mais engraçado, gosta de fazer campeonato, no play, de quem faz mais gol; a minha avó gosta de conversar, saber como foi o meu dia, o que quero fazer, o que quero comer...”.

Quando os avôs têm uma postura mais engajada com seus netos, esta normalmente não acontece no cuidado instrumental, como as avós, mas nas brincadeiras que eles proporcionam aos pequenos, quase sempre divertidas e agitadas, que fazem com que as crianças os caracterizem como engraçados e brincalhões (Harper, 2006; Ramos, 2011).

Como podemos observar, os avôs parecem ter uma imagem bastante ambivalente. Por um lado, os relacionamentos com os netos tendem a ser menos calorosos do que aqueles construídos com as avós, o que evidencia um envolvimento menor dos homens nesta relação. Por outro lado, encontramos em alguns avôs sistemáticos e esporádicos -, momentos de ludicidade que os colocam em lugar de destaque diante daqueles vividos na companhia das avós.

Apesar de não haver diferenças significativas entre os dois sexos no que diz respeito ao desejo de convívio com as famílias, diferenças surgem quando as mulheres se destacam no exercício de trabalhos internos, atividades sociais e religiosas. Os homens se sobressaem em prestações de serviço externo e práticas esportivas. As diferenças entre os dois sexos evidenciam as características tradicionalmente mais altruístas por parte das mulheres e a sua dedicação voltada ao cuidado (Pires, 2010).

Mas as diferenças de gênero não se encerram nos estilos ou nos modos de interação assumidos pelos avôs e pelas avós. A linhagem também é um recorte de gênero importante, que influencia no modo e na intensidade do contato estabelecido entre eles e seus netos. 
Pesquisas mostram que, nas sociedades ocidentais, os laços com o lado materno tendem a ser mais fortes do que aqueles com o lado paterno, em virtude da centralidade das mulheres nas relações familiares, da solidariedade feminina e da matrilinearidade (Motta, 2004; Attias-Donfut, 2004; Harper, 2006; Kipper, \& Lopes, 2006; Mann, Khan, \& Leeson, 2009; Marcondes, 2010; Ramos, 2011).

\section{Núcleo Recurso: Modo de contato das linhagens: solidariedade feminina $e$ matrileniaridade}

\section{Solidariedade feminina}

Por meio do suporte emocional oferecido, o neto de tempo integral declara: "Ela cuida de mim para a minha mãe trabalhar e estudar". Assim, as avós permitem que a segunda geração continue trabalhando e estudando.

Essa solidariedade também ocorre entre noras e sogras. Segundo Ramos (2011), quando as relações entre noras e sogras são boas, garantem que o contato com a linha paterna não se perca, como explica a neta esporádica: “Às vezes a minha mãe liga prá minha avó que é mãe do meu pai e pergunta se eu posso ir prá lá, aí eu vou”. Por outro lado, a outra neta de tempo integral associa o cuidado à figura materna: "Ela é uma segunda mãe".

\section{Matrileniaridade}

A literatura aponta que grande parte dos cuidadores pertence à linhagem matrilinear (Kipper, \& Lopes, 2006), e que a intensa convivência, assim como o cuidado que elas direcionam aos netos, são vistos por eles como fatores importantes, o que faz com que as crianças, muitas vezes, as identifiquem como uma "segunda mãe", comentado pelos seguintes netos: "Ela me ajuda nas tarefas escolares quando não sei" (neta integral); "Ela faz comidinha gostosa, lê histórias para mim quando eu vou em sua casa” (neto sistemático); "me dá remédio na hora certa”(neto esporádico). 
A ênfase nas avós maternas tem perpetuado a matrilinearidade dos estudos sobre avós, apoiando a ideia de que a continuidade familiar tem mais probabilidades de persistir através das mulheres e que as mulheres, independentemente da idade, têm mais probabilidades de conservar laços mais estreitos com filhos e netos (Harper, 2006).

Em relação ao papel feminino, Attias-Donfut (2004) informa que, o cuidador é um papel tradicionalmente exercido pelas mulheres. $O$ surgimento da sociedade multigeracional ampliou este papel com o aparecimento de uma geração de mulheres que a autora designou como "pivô", pois ajuda ao mesmo tempo, os pais idosos, os filhos e os netos. A autora a denomina como uma rede de ajuda mútua que se estrutura nas relações multigeracionais femininas, pois as mulheres da família se ajudam mutuamente e assim perfazem um ciclo de reciprocidades.

As mulheres tomam conta de seus filhos, depois dos netos, ao mesmo tempo em que se ocupam dos seus pais e, quando ficam mais velhas, recebem o apoio de seus filhos, principalmente, das filhas e noras em um ciclo de reciprocidade diretas (por parte dos filhos pela ajuda que eles mesmos receberam), mas, também, indiretas (pela ajuda que deram aos seus próprios pais) (Attias-Donfut, 2004, p. 102).

É importante ressaltar, neste estudo, que da linhagem materna e paterna, a figura mais presente na vida das crianças são as avós e os avôs maternos, coabitando ou não, enquanto a avó paterna foi citada mais do que os avôs paternos.

Como bem destaca Britto da Motta, “[...] as mulheres 'tecem' ou intermediam as relações domésticas e de família, mantendo tradicionalmente unidas duas ou três gerações" (2004, p. 6). Por isso, salvo algumas situações de conflito ou de impossibilidades, as jovens mães costumam buscar mais apoio de suas próprias mães do que de suas sogras no cuidado das crianças, intensificando o contato com a linhagem materna.

Além disso, a avó materna é também considerada mais influente do que os avós paternos, em termos de proximidade, estreitamento de laços, e por proporcionar uma sensação de segurança (Harper, 2006; Mann, Khan, \& Leeson, 2009).

Segundo Marcondes (2010), duas possíveis causas para a matrilinearidade são: a ausência do homem, ou maior confiança da mãe em sua própria genitora como cuidadora secundária, pois, historicamente, há no Brasil, muitas mulheres sem companheiros fixos. Como aponta o autor: 
[...] intensos fluxos migratórios, uma alta mortalidade masculina e outros aspectos da vida social, relacionados aos contextos socioeconômicos e culturais historicamente tornaram os arranjos monoparentais femininos algo há muito presente na realidade das famílias nordestinas, destacadamente nos segmentos sociais mais pobres (Marcondes, 2010, p. 6).

$\mathrm{Na}$ presente pesquisa, foi possível constatar que a ausência dos avôs na convivência dos netos por motivo de falecimento e separação conjugal.

O índice de divórcios não é alto apenas entre a população mais jovem. Ele também tem aumentado no grupo com mais de 60 anos que, devido à maior longevidade e às mudanças no estilo de vida, tem optado por redefinir seus relacionamentos conjugais e sua satisfação pessoalmente mesmo em uma idade mais avançada (Ramos, 2011).

Segundo dados do IBGE (2010), entre 2003 e 2006 o número de pedidos de divórcio nessa faixa etária aumentou em 27,8\% quando feitos pelos homens, e 29,3\% quando feitos pelas mulheres.

Nesta pesquisa, um dos netos possuía avós maternos divorciados: enquanto o menino tem um relacionamento próximo e intenso com a sua avó, o contato com o avô materno é distante e quase inexistente, ocorrendo apenas por telefone: "Meu avô não mora com a minha avó, de vez em quando ele fala comigo por telefone" (neto integral). Contudo, a qualidade da relação também tende a se modificar, principalmente quando ela vem acompanhada da desaprovação dos filhos (Attias-Donfut, 2002).

\section{Núcleo Força - Preferência dos gêneros}

Em relação à preferência, a literatura aponta que a eleição afetiva dos avós em relação aos netos, e dos netos em relação aos avós, acontece principalmente na infância, momento em que há uma redefinição dos papéis familiares, em virtude do nascimento do novo descendente, e momento em que essas duas gerações tendem a conviver por mais tempo, principalmente nas situações de cuidado e guarda dos netos (Ramos, 2011). 
Quando os elos são fortes, os avós tendem a ocupar "um bom espaço no coração" (neta integral) das crianças, e elas mostram que essa afeição tem amor suficiente para durar a vida inteira, estendendo-se durante a adolescência e a fase adulta. O neto integral, por exemplo, diz assim: "Eu gosto tanto da minha avó que se a minha mãe morrer, eu sei que ela cuidaria bem de mim". Isso mostra a singularidade e a importância que certos avós ocupam na vida de seus netos.

Contudo, a predileção não acontece espontaneamente, sendo atravessada por diferentes fatores que influenciam essa relação, tais como: a assiduidade do contato, a frequência com que os avós cuidam de seus netos, as afinidades entre eles, as brincadeiras, as condições de saúde dos avós, e a própria troca de presentes e serviços que, como destaca Peixoto, "traduzem a atenção com o outro e alimentam a afeição" (2004, p. 100).

Para o neto sistemático, por exemplo, sua avó materna é sua "avó preferida porque ela é muito legal, divertida, leva a passear no shopping quando [ele vai] na casa dela". O mesmo acontece com o neto esporádico, que acha os seus avós muito legais, porque "O meu avô joga totó no play e minha avó brinca na piscina comigo". A predileção pela linha materna tende a ser mais intensa do que a convivência com a linhagem paterna tanto nas famílias nucleares, monoparentais, quanto nas conviventes.

As motivações que impulsionam as escolhas das crianças podem ser de várias ordens. Em relação aos avôs, sejam eles paternos ou maternos, o critério de escolha normalmente recai sobre a brincadeira e a diversão, aspectos que, como comentei anteriormente, caracterizam o modo como os homens mais engajados vivem esse papel. Para as avós, os critérios tendem a ser mais variados, mas o jogo e a ludicidade também são fatores importantes, tendo sido destacados como critério de preferência principalmente para as avós paternas: “Quando eu vou na casa da minha avó, ela joga dama, me ensina a bordar, faz coisas diferentes que a outra avó faz comigo que é de me cuidar", declara a neta esporádica. Outro critério que impulsiona as escolhas dos netos é a coabitação. Quando elas moram com os avós, esse aspecto é ainda mais visível " $E u$ cuido dela e ela cuida de mim" (neto integral), da mesma forma pensa a neta sócioafetiva: "Ela é a minha segunda mãe; ela cuida de mim". 
Morar junto parece ser, de fato, um fator determinante quanto à predileção e, novamente, a avó materna foi a mais lembrada (mesmo quando o avô também morava junto), mostrando que a convivência é um critério importante nos elos de afeição, que possibilitam o cuidado, a ajuda e a reciprocidade.

As avós cuidadoras também costumam ser emocionalmente mais próximas de seus netos. Um contato mais assíduo possibilita a criação de vínculos mais fortes, que são permanentemente reforçados pelo cotidiano (Cunha; Matos, 2010; Harper, 2006).

As relações intergeracionais são, também, influenciadas pela frequência de encontros entre avós e netos. De acordo com Oliveira (2007), quanto mais avós e netos se encontram, menor o impacto das relações dos avós com seus filhos sobre as relações avós-netos.

É claro que uma convivência mais intensa também pode acontecer quando avós e netos não dividem a mesma casa. Avós que não moram junto, mas que são cuidadores integrais, cuidam deles no turno oposto ao da escola, diariamente, que convivem durante algum dia específico da semana, ou ajudam quando solicitados pelos filhos a assumirem o cuidado, também ocupam um lugar especial na vida das crianças, principalmente pelas avós maternas que são menos exigentes, contribuindo para a eleição de suas predileções, como declara a neto esporádico "Nunca sei o dia em que vou para a casa dos meus avós, gosto de ir prá lá porque tenho liberdade...mais tempo de ficar no computador".

Attias-Donfut, Lapierre, e Segalen (2002) declaram que existem componentes que também são da ordem do afetivo, o que faz com que os aspectos psicológicos dos comportamentos não possam ser negligenciados na análise dessas relações.

Por isso, nem sempre a motivação da preferência se dá pela proximidade de residência, às vezes pode vir de longe.

Esses são aspectos relevantes tanto para os meninos quanto para as meninas, não havendo grandes diferenças de gênero quanto às expectativas e experiências intergeracionais das crianças entrevistadas. 


\section{Considerações Finais}

Os avós de hoje são percebidos ajudando na condução da vida familiar, tornando-se figuras ativas e presentes, nos moldes do pensamento de Bronfenbrenner (1996). Desse ponto de vista, os avós emergem no cenário contemporâneo como uma forma de apoio social com que os pais contam rotineiramente para a tarefa de cuidar de suas crianças e educá-las.

Na convivência cotidiana em família, os avós se preocupam em passar para os descendentes, em especial os netos, as lições por eles extraídas dos acontecimentos de suas próprias histórias de vida.

O presente estudo teve como objetivo verificar se, e como, as relações entre avós e netos têm conformações diversas a partir de diferenças associadas a gênero. Concluise haver diferença associada ao gênero do avô/avó na relação com os netos. As avós são mencionadas associadas aos cuidados internos, enquanto que os avôs são mencionados associados a atividades externas. Além disso, o local onde habitam determina hábitos que se refletem igualmente nas brincadeiras. Convivendo em ambientes fechados, a tendência será por jogos internos.

As atividades lúdicas entre avós e netos de tempo integral tendem a ocorrer em espaços internos, como jogos educativos e eletrônicos, enquanto os avós sistemáticos e esporádicos priorizam brincadeiras em espaços externos, como praia, piscina, jogos de salão e futebol, nos parquinhos e, especialmente, nos playgrounds.

A percepção que as crianças têm em relação aos avós é positiva. As avós maternas são preferidas porque elas estão mais envolvidas no cuidado das crianças, ajudando-as nas pequenas e nas grandes tarefas. $\mathrm{O}$ fato de ser mais mencionada (mesmo quando o avô também morava junto) mostra que a convivência é um critério importante nos elos de afeição que possibilitam o cuidado, a ajuda e a reciprocidade. A acrescentar o laço de solidariedade entre mulheres e o de matrilenearidade na consideração das diferenças entre avós e avôs, indicando que instâncias do tempo social e mesmo de tempo mais longos podem estar presentes nestas relações.

Devemos igualmente remarcar a importância dos seguintes aspectos: a) a comunicação bidirecional em contraposição à unidirecional; b) a existência de informações precisas e fidedignas; c) o sentimento de objetivos comuns de dois ou mais sistemas envolvidos; d) a confiança mútua; e) o equilíbrio de poder. São elementos que favorecem o desenvolvimento de todos os participantes. 
Como, em geral, as crianças têm maior domínio das novas tecnologias do que seus avós, isso significa que há uma interação de mutualidade e reciprocidade em torno do computador e dos jogos eletrônicos, por meio dos quais essas duas gerações se ajudam, brincam e interagem e estabelecem modos alternativos de domínio e poder.

No entanto, os jogos e as brincadeiras de hoje em dia não são apenas feitos de computadores, celulares e videogames, mas de outros brinquedos e brincadeiras que não perderam o seu espaço.

Ressaltamos que o processo de urbanização das cidades trouxe mudanças para os modos de morar e viver: a vida das crianças se dá cada vez mais em apartamentos, condomínios fechados e shopping centers, onde o contato com a natureza é quase inexistente; mesmo assim, a casa dos avós é um lugar de diversão, adaptação para criar ambientes interativos, lúdicos e acolhedores para seus netos e onde as crianças podem brincar com seus irmãos e primos. Avós e netos se adaptam às novas circunstâncias de vida, modificando as formas de interagir e brincar com o intuito de continuar interagindo e continuar brincando.

\section{Referências}

Associação Brasileira de Empresa de Pesquisa - ABEP (2012). Dados com base no levantamento sócio-econômico. IBOPE. Recuperado em: 20 setembro, 2015 de: http://www.abep.org/criterio-brasil.

Attias-Donfut, C., Lapierre, N, \& Segalen, M. (2002). Le nouvelesprit de famille. Paris, France: Éditions Odile Jacob.

Attias-Donfut, C. (2004). Sexo e envelhecimento. In: Peixoto, C. (Org.). Família e envelhecimento, 1, 85-108). Rio de Janeiro, RJ: FGV.

Bronfenbrenner, U. (1995). Uma família e um mundo para o Bebê XXI: sonho e realidade. In: Gomes-Pedro, J. (Org.). Bebé XXI. Criança e família na viragem do século. Lisboa, Portugal: Fundação Calouste-Gulbenkian.

Bronfenbrenner, U. (1996). A ecologia do desenvolvimento humano: experimentos naturais e planejados. Veronese, M. A. V., Trad. Porto Alegre, RS: Artes Médicas. (Original publicado em 1979).

Bronfenbrenner, U., \& Morris, P. (1998). The ecology of developmental processes. In: Damon, W. (Org.). Handbook of child psychology, 1, 993-1027. New York, NY: John Wiley \& Sons.

Coutrim, R. M. (2006). Idosos trabalhadores: perdas e ganhos nas relações intergeracionais. Sociedade e Estado, 21(2), 367-390. Recuperado em 20 setembro, 2015, de: http://www.scielo.br/pdf/se/v21n2/a04v21n2.pdf. 
Cunha, B., \& Matos, P. (2010). Relações intergeracionais: significados de adolescentes sobre avós e idosos. In: VII Simpósio Nacional de Investigação em Psicologia. Universidade do Minho, Portugal, 4-6 fev. Recuperado em 20 setembro, 2015, de: https://repositorio-aberto.up.pt/bitstream/10216/21487/2/87927.pdf.

Goldfarb, D., \& Lopes, R. (2006). Avosidade: a família e a transmissão psíquica entre gerações. In: Freitas, E. V., \& Py, L. (Orgs.). Tratado de Geriatria e Gerontologia. (2 ${ }^{\mathrm{a}}$ ed.). Rio de Janeiro, RJ: Guanabara-Koogan. Recuperado em 13 novembro, 2015, de: http://www.portaldoenvelhecimento.org.br/psico/psico103.htm.

Harper, S. (2006). Papéis dos avós nas famílias multigeracionais dos nossos dias. Revista Povos e Culturas - Os avós como educadores, 10, 25-38. Lisboa (Portugal): Universidade Católica Portuguesa. Recuperado em 08 setembro, 2013, de: http://www.ucp.pt/site/resources/documents/CEPCEP/POVOS\%20E\%20CULTURAS_ 10.pdf.

Instituto Brasileiro de Geografia e Estatística. (IBGE). (2010). Perfil dos idosos responsáveis pelos domicílios no Brasil, 2000. Série Estudos e Pesquisas. Informação Demográfica e Socioeconômica, n. ${ }^{\circ}$ 9, Rio de Janeiro, RJ: Autor. Recuperado em 14 setembro, 2015, de:

http://www.ibge.gov.br/home/estatistica/populacao/perfilidoso/perfidosos2000.pdf.

Kipper, C., \& Lopes, R. (2006). O tornar-se avó no processo de individuação. Psicologia: Teoria e Pesquisa, 22(1) 29-34. Recuperado em 20 setembro, 2015, de: http://www.scielo.br/pdf/ptp/v22n1/29841.pdf.

Mann, R., Khan, H., \& Leeson, G. (2009). Age and gender differences in grandchildren's relations with their maternal grandfathers and grandmothers. Oxford Institute of Ageing Working Papers, 1-20. Recuperado em 20 setembro, 2015, de: http://www.ageing.ox.ac.uk/download/81.

Marcondes, G. (2010). Uns ficam, outros vão e alguns voltam: composição e dinâmicas dos grupos domésticos em Salvador. In: Encontro Nacional de Estudos Populacionais, 17, Caxambu: ABEP 20-24 set. Recuperado em 20 setembro, 2015, de: http://www.abep.nepo.unicamp.br/encontro2010/docs_pdf/tema_12/abep2010_2238.pdf.

Moreira, L. V. C., Rabinovich, E. P., \& Silva, C. N. (2009). Olhares de crianças baianas sobre família. Paidéia, 19(42), 77-85. Recuperado em 20 setembro, 2015, de: http://www.scielo.br/scielo.php?script=sci_arttext\&pid=S0103-863X2009000100010.

Motta, A. B. da. (2004). Sociabilidades possíveis: idosos e tempo geracional. In: Peixoto, C. E. (Org.). Família e envelhecimento. Rio de Janeiro, RJ: FGV.

Pedrosa, A. S. (2006) Homens idosos avôs: significado dos netos para o cotidiano. Dissertação de mestrado em Gerontologia. Pontifícia Universidade Católica de São Paulo, SP. Recuperado em 20 setembro, 2015, de: http://bases.bireme.br/cgibin/wxislind.exe/iah/online/.

Peixoto, C. E. (2004). Família e envelhecimento. Rio de Janeiro, RJ: FGV.

Pires, M. de F. (2010). Presença e papel dos avós: estudo de caso. Dissertação de mestrado em Ciências da Educação. Aveiro (Portugal): Departamento de Educação, Universidade de Aveiro. Recuperado em 09 dezembro 2015, de: http://ria.ua.pt/bitstream/10773/3601/1/4537.pdf. 
Ramos, A. C. (2011). Meus avós e eu: relações intergeracionais entre avós e netos na perspectiva de crianças. Tese de doutorado em Educação. Universidade Federal do Rio Grande do Sul, Porto Alegre, RS. Recuperado em 20 setembro, 2015, de: http://www.lume.ufrgs.br/handle/10183/32306.

Ramos, A. C. (2012). "Avó é feminino e avô é masculino": relações de gênero e entre gerações na perspectiva das crianças. In: XV Encontro de Ciências Sociais do Norte e Nordeste e Pré-Atlas Brasil, Universidade Federal do Piauí. Recuperado em 20 setembro, 2015, de: http://www.sinteseeventos.com.br/ciso/anaisxvciso/resumos/GT1001.pdf.

Rodrigues, J. P. (2008). Práticas e saberes das avós no cuidar das crianças: uma abordagem intergeracional e intercultural. Dissertação de mestrado em Comunicação em Saúde. Universidade Aberta, Lisboa. Recuperado em 20 setembro, 2015, de: http://repositorioaberto.uab.pt//handle/10400.2/728.

Saraceno, C., \& Naldini, M. (2001). Sociologia della famiglia. Bologna, Italia: Mulino.

Scherer, M. (2009). A globalização e a infância: reflexos e reflexões nas falas das crianças. In: X Encontro Nacional de Prática de Ensino em Geografia. Porto Alegre, RS, 30-02 set. Recuperado em 20 setembro, 2015, de: http://www.agb.org.br/XENPEG/artigos/GT/GT6/tc6\%20(4).pdf.

Silva, A. P. (2010) Percepções de avós cuidadoras maternas sobre a criação e educação dos netos. Dissertação de mestrado em Psicologia. Universidade Federal de Juiz de Fora, MG. Recuperado em 20 setembro, 2015, de: http://www.ufjf.br/ppgpsicologia/files/2010/01/Anna-Paula-Gomes-da-Silva.pdf.

Smorti, M., \& Tschiesner, R., \& Farneti, A. (2012). Grandparents-grandchildren relationship. Procedia - Social and Behavioral Sciences. Estudo, 46(1), 895-898. Recuperado em 20 setembro, 2015, de: http://www.sciencedirect.com/science/article/pii/S1877042812013481.

Recebido em 11/12/2016

Aceito em 30/03/2017

Rosa Maria da Motta Azambuja - Pedagoga. Mestre e Doutora em Família na Sociedade Contemporânea (UCSal). Professora de Graduação e Pós-Graduação, Faculdade Batista Brasileira (FBB).

E-mail: psicoazambuja@ hotmail.com 
Elaine Pedreira Rabinovich - Psicóloga clínica. Mestrado e Doutorado pelo IPUSP; Pós-doutorado IPUSP e FFCL-USP/RP. Professora do Programa de Pós-Graduação em Família na Sociedade Contemporânea/UCSal; Coordenadora do Grupo de Pesquisa Família, (auto)biografia e poética/UCSal.

E-mail: elainepr@brasmail.com.br 